\title{
Experimento de condução térmica com e sem uso de sensores e Arduino+*
}

Cleci Teresinha Werner da Rosal

Marco Antonio Trentin ${ }^{2}$

Programa de Pós-Graduação em Ensino de Ciências e Matemática

Álvaro Becker da Rosa ${ }^{3}$

Alisson Cristian Giacomelli ${ }^{4}$

Curso de Física

Universidade de Passo Fundo

Passo Fundo - RS

\section{Resumo}

Este trabalho constitui-se no relato da realização de uma atividade experimental envolvendo o conteúdo de condução de calor. O principal objetivo é servir como material de apoio para que professores, tanto de Ensino Médio como de Ensino Superior, possam reproduzir a experiência com os seus alunos. Primeiramente foram feitas algumas considerações importantes sobre o fenômeno de transmissão de calor por condução. $\mathrm{Na}$ sequência, foi apresentada uma proposta de roteiro para a construção do equipamento com materiais alternativos e de baixo custo. A realização da atividade experimental foi dividida em duas partes: na primeira, foram utilizados termômetros convencionais para a realização das medidas de temperatura; na segunda, foram inseridos os sensores de temperatura e a placa Arduino, e o experimento foi assistido pelo PC. Por meio dessas atividades, foi possível perceber as vantagens e limitações do uso dessas tecnologias na realização do experimento, assim como fazer uma projeção do emprego desse método para outros experimentos envolvendo medidas de temperatura.

\footnotetext{
${ }^{+}$Thermal conductivity experiment with and without the use of sensors and Arduino

* Recebido: abril de 2015.

Aceito: novembro de 2015.

1 E-mail: cwerner@upf.br

2 E-mail: trentin@upf.br

3 E-mail: alvaro@upf.br

${ }^{4}$ E-mail: alissongiacomelli@upf.br
} 
Palavras-chave: Condução de calor; Experimentos de Física com Arduino; Ensino de Física.

\begin{abstract}
This work is a report of the performance of an experimental activity involving the content of heat conduction. The main objective is to serve as supporting material for teachers, both of High Schools and Higher Education, so they may reproduce the experience with their students. Firstly, some important considerations were made on the phenomenon of heat transmission by conduction. Then, a script on how building the equipment with alternative and inexpensive material was presented. The performance of the experimental activity was divided in two parts: in the first part, conventional thermometers were used to measure temperature; in the second part, temperature sensors and the Arduino board were inserted, and the experiment was observed through a PC. It was possible, with these activities, to realize the advantages and limitations of using these technologies in experiment performance, as well as to project the application of this method for other experiments involving temperature measurements.
\end{abstract}

Keywords: Heat conduction; Physics experiments with Arduino; Physics teaching.

\title{
I. Introdução
}

Fenômenos envolvendo os mecanismos de transmissão de calor estão diretamente relacionados com o cotidiano das pessoas. A blusa de lã recomendável em um dia em que a temperatura está baixa, a garrafa térmica que limita o resfriamento do café, entre outras situações e dispositivos, são exemplos da aplicação do estudo de temperatura. A sua simples observação espontânea no cotidiano remete à ideia de que o calor pode ser transmitido com maior ou menor facilidade, ao mesmo tempo em que remete à confusão na compreensão científica entre calor e temperatura. Diante disso, há a necessidade de esclarecer essas limitações conceituais, especialmente no contexto escolar, cuja responsabilidade é voltada à cientificidade do conhecimento.

Em termos da transmissão de calor, assunto específico deste artigo, identifica-se três formas: condução, convecção e irradiação. Embora em alguns casos possa predominar uma delas, geralmente a transmissão ocorre de modo associado, envolvendo os três processos simultaneamente. A transmissão de calor por condução ocorre devido ao choque direto entre as moléculas de um material, não ocorrendo um deslocamento significativo destas ao longo do corpo. Ainda que seja a forma de transferência de calor característica dos sólidos, a condução também 
pode ocorrer em menor escala nos fluidos, desde que as suas moléculas não se movimentem ao longo da amostra. Já a convecção, que é característica dos fluidos, encontra-se associada à possibilidade de movimentação das moléculas que constituem o material. As duas formas de transmissão de calor definidas necessitam de um meio material para ocorrer, porém esse não é o caso da terceira forma, a irradiação. Nela, o calor é transmitido por meio de ondas eletromagnéticas, as quais, por sua vez, podem se propagar, inclusive, no vácuo.

Com o intuito de evidenciar tais formas de transmissão de calor no ensino médio ou até mesmo no ensino superior, recorre-se a um experimento com uso de materiais alternativos, podendo ou não estar associado a dispositivos eletrônicos e à possibilidade da coleta de dados com o uso do computador. Dentre os aspectos envolvidos na transmissão de calor, o experimento proposto analisou a condutividade térmica de dois materiais (metais) e a transição do fluxo de calor em regime transiente para estacionário. A atividade experimental proposta no presente estudo foi estruturada em duas possibilidades: a primeira utiliza termômetros convencionais para a realização das medidas de temperatura, recorrendo à construção de gráficos por meio de uma planilha de cálculo (Excel®, da Microsoft $\left.{ }^{\circledR}\right)$; a segunda refere-se à utilização de sensores analógicos de temperatura para a coleta dos valores de temperatura. Nesse último caso, os sensores foram conectados a uma placa Arduino, e esta, por sua vez, conectada a um computador para a geração de um gráfico, em tempo real, das temperaturas no experimento.

Optou-se por apresentar o estudo com duas alternativas para utilização em sala de aula, sendo ambas assistidas ou apoiadas por computador, porque, conforme Cavalcante (2011), é inegável a utilidade desse equipamento como ferramenta de ensino nas mais diversas áreas. Além disso, a autora destaca que a dinâmica de qualquer processo envolvendo esse tipo de tecnologia pode se mostrar muito atraente para o estudante.

Diante do exposto, apresenta-se o principal objetivo do trabalho que o de servir como material de apoio para que a atividade experimental proposta possa ser realizada em sala de aula, sem necessidade de aparatos experimentais sofisticados. A metodologia para o desenvolvimento da atividade fica a critério do professor, que irá aplicá-la de acordo com sua compreensão e concepção do processo de ensino-aprendizagem, bem como adaptada ao nível de ensino em questão.

Como forma de exemplificar uma possibilidade de uso, apresenta-se a descrição do experimento acompanhado de um conjunto de dados qualitativos referentes ao experimento. Além disso, é exposta uma reflexão sobre as possibilidades de discussões inerentes aos resultados do experimento.

Estruturalmente, o artigo inicia por uma revisão referente a aspectos fundamentais e conceituais da condução de calor. A seguir, apresenta um guia para a construção do equipamento e, na sequência, a proposta de uso metodológico. Ao final e antes das últimas considerações, divulga a análise dos dados quantitativos de temperatura obtidos experimentalmente com a realização da atividade proposta. 


\section{Considerações sobre a condução de calor}

A condução de calor ocorre pela transmissão de energia térmica por meio de impactos entre as moléculas de um corpo, sem que haja um deslocamento apreciável dessas moléculas ao longo do corpo. A condução térmica que ocorre dessa forma não se mostra tão significativa como a que ocorre pelo deslocamento de elétrons de um átomo para outro ao longo do material. Esse fenômeno ocorre uma vez que, em alguns átomos, os elétrons não estão tão fortemente ligados ao núcleo, dos quais, em decorrência disso, podem se desprender, deslocando-se para átomos vizinhos e transportando, assim, energia térmica ao longo do material. A esse fenômeno chama-se "condução térmica". Esses elétrons, denominados "elétrons livres", são os principais responsáveis para que um material seja considerado um bom ou mau condutor de calor, assim como um bom ou mau condutor de eletricidade, respectivamente.

Para discutir a condução térmica Hewitt (2002) descreve uma situação na qual uma agulha de metal está sendo aquecida pelo fogo em uma de suas extremidades. Diz o texto: "O fogo faz os átomos da extremidade aquecida moverem-se cada vez mais rapidamente. Em consequência, esses átomos e elétrons livres colidem com seus vizinhos e assim por diante. Esse processo de múltiplas colisões continua até que o aumento no movimento seja transmitido a todos os átomos, e o corpo inteiro torne-se quente. A condução de calor ocorre por meio de colisões atômicas e eletrônicas" (p. 281).

Para expressar a condução de calor ao longo de um corpo, define-se o conceito de "fluxo de calor". O fluxo consiste na quantidade de calor que atravessa o corpo em um determinado intervalo de tempo. O fluxo de calor - ou a condução térmica - ocorre somente quando existe uma diferença de temperatura em pontos espacialmente distribuídos ao longo do material. O fluxo de calor unidimensional em um determinado material isotrópico é dado, dentre outras, pela seguinte relação matemática:

$$
\Phi=\frac{\Delta Q}{\Delta t}=K \cdot A \cdot \frac{\Delta T}{\Delta x}
$$

Sendo:

$\Phi$ é o fluxo de calor [cal/s];

K é a condutividade térmica do material $\left[\mathrm{cal} / \mathrm{s.cm} .{ }^{0} \mathrm{C}\right]$;

A é a área da seção transversal à direção do fluxo, $\left[\mathrm{cm}^{2}\right]$

$\frac{\Delta T}{\Delta x}$ é o gradiente de temperatura, ou seja, a razão entre a variação de temperatura e a distância na direção do fluxo de calor.

Para que se possa compreender melhor o conceito de fluxo, será utilizado o exemplo de uma barra metálica de comprimento L: serão adotados como pontos de referência A, B e C; A e B estão situados nas extremidades da barra e $\mathrm{C}$, em um ponto central em relação ao comprimento L. Inicialmente, a barra está à temperatura ambiente, e praticamente não existe diferença de temperatura entre os pontos A, B e C. Ao se transferir calor para a barra no ponto A, 
a temperatura da barra nesse ponto começa a aumentar. No transcorrer do tempo, as temperaturas nos pontos B e $\mathrm{C}$ também começam a aumentar. Nesse momento, a temperatura em todos os pontos escolhidos é variável, assim como o fluxo, consequentemente. Chama-se esse fluxo variável de "fluxo transiente de calor". Depois de um determinado intervalo de tempo, a temperatura em cada ponto da barra para de variar e estabelece-se o que se chama de fluxo estacionário de calor. Percebe-se que as temperaturas nos pontos A, B e C não mais variam e que a quantidade de calor que entra na seção em cada ponto é a mesma que sai. As temperaturas nos pontos A, B e C são constantes, porém não são iguais. A temperatura no ponto A é maior do que a no ponto $\mathrm{B}$, e esta, por sua vez, é maior do que a no ponto $\mathrm{C}$, diferença que ocorre linearmente na direção do fluxo de calor. O tempo necessário para que se estabeleça o fluxo estacionário em um corpo depende, basicamente, da condutividade térmica $(\mathrm{k})$ do material que constitui o corpo; ou seja, materiais com maiores valores de $\mathrm{k}$ (bons condutores) atingem mais rapidamente o regime de fluxo estacionário, e materiais com menores valores de $\mathrm{k}$ (maus condutores) levam mais tempo para atingi-lo. O fato relevante neste experimento é que se pode facilmente confrontar hipóteses sobre a evolução e os valores finais das temperaturas com os resultados que serão obtidos, com a demonstração do que é regime transitório e do significado de fluxo de calor.

\section{Construção do equipamento}

O equipamento proposto foi construído utilizando materiais alternativos e de baixo custo, como forma de viabilizar e facilitar a sua reprodução nas escolas. É importante ressaltar que o experimento pode ser construído de outras formas, a fim de adaptá-lo aos materiais e às ferramentas disponíveis. A relação dos materiais necessários para a construção do experimento está listada a seguir: uma lata de azeite ou semelhante (tem que ser metálica e deve caber uma lâmpada incandescente em seu interior); um soquete para lâmpada incandescente comum; aproximadamente 50 a $60 \mathrm{~cm}$ de fio cabo paralelo; um plugue macho 2 P; uma lâmpada incandescente de $60 \mathrm{~W}$ ou $100 \mathrm{~W}$; suporte de madeira ou MDF de aproximadamente $20 \mathrm{~cm}$ x $8 \mathrm{~cm}$; uma barra metálica de alumínio com $42 \mathrm{~cm}$ de comprimento, $2 \mathrm{~cm}$ de largura e $3 \mathrm{~mm}$ de espessura (obtida em oficinas de esquadrias de alumínio); e uma barra metálica de cobre com $42 \mathrm{~cm}$ de comprimento, $2 \mathrm{~cm}$ de largura e $3 \mathrm{~mm}$ de espessura (obtida em lojas de materiais elétricos).

A Fig. 1 consiste em uma fotografia dos materiais utilizados para a construção do equipamento.

Para a construção do equipamento, é necessário inicialmente que se monte o circuito com o soquete para a lâmpada, o cabo e o plugue $2 \mathrm{P}$. Na sequência, é necessário que se prenda o soquete no suporte de madeira. Deve-se remover o fundo da lata de azeite, fixando-a no suporte de madeira como demonstrado na Fig. 2. Para fixar as barras de alumínio e cobre na lata de azeite, foi feito um corte horizontal na lata. As barras foram colocadas nesse corte e presas com um rebite (elas podem ser presas com cola epóxi), como mostra a Fig. 3. 


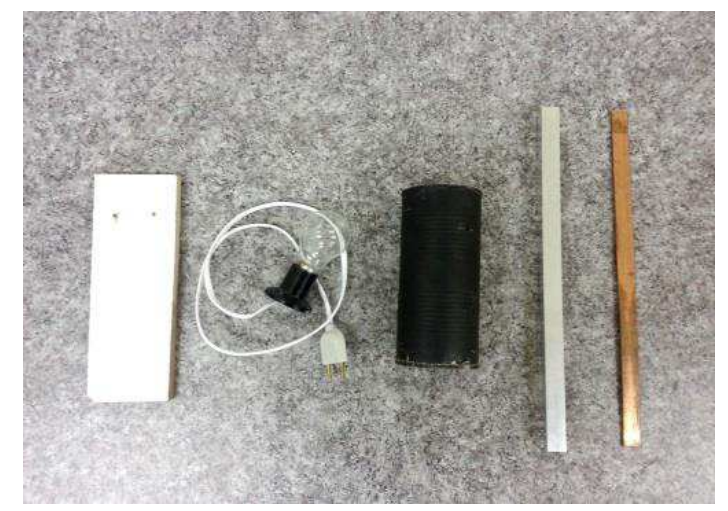

Fig. 1 - Materiais utilizados para a construção do equipamento.

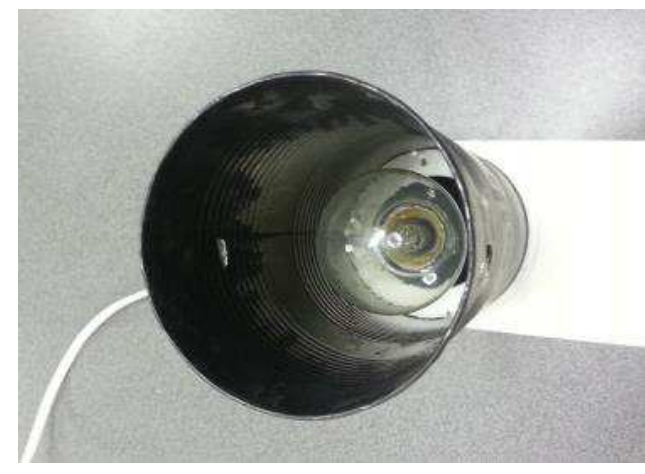

Fig. 2 - Fixação da lata no suporte.

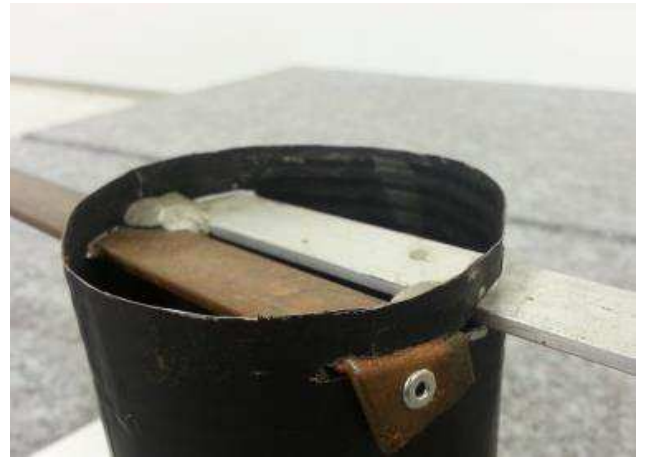

Fig. 3 - Fixação das barras metálicas.

Para reduzir a troca de calor com o meio, reduzindo o tempo para a realização da experiência, construiu-se uma tampa que foi colocada sobre a lata. Essa tampa também pode ser uma pequena tampa de panela, eliminando, assim, a necessidade de se construir uma exclusivamente para a realização da experiência.

Na Fig. 4, apresenta-se o equipamento pronto para ser utilizado.

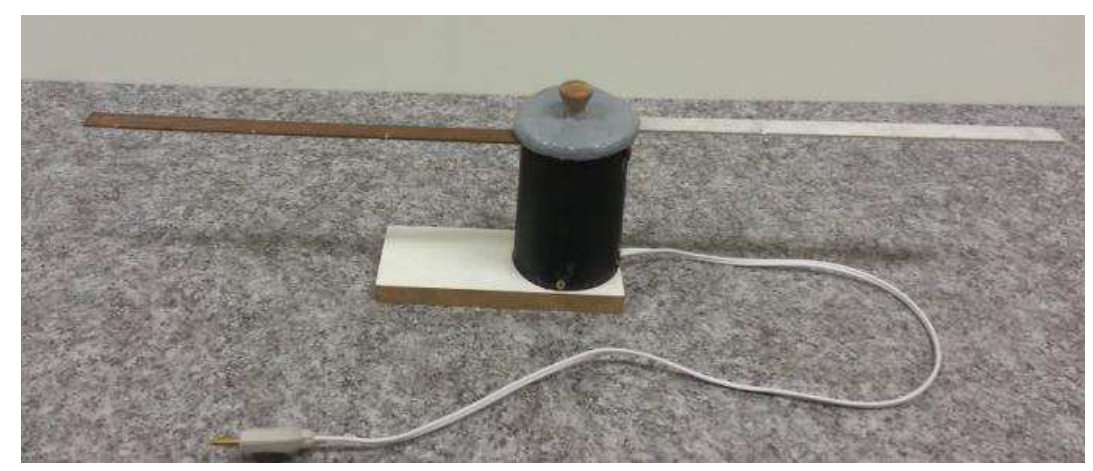

Fig. 4 - Equipamento pronto para ser utilizado. 


\section{Arranjo experimental}

O experimento foi realizado de duas formas distintas. Na primeira montagem, foram utilizados termômetros convencionais para a coleta dos valores de temperatura e um cronômetro para a medição dos intervalos de tempo. Para a montagem dos gráficos de temperatura em função do tempo, os dados foram anotados manualmente e, posteriormente, plotados com a ajuda de uma planilha eletrônica de cálculo (Excel®, da Microsoft®). Na segunda montagem, foi utilizado o mesmo equipamento, porém foram utilizados sensores eletrônicos de temperatura LM35 para a coleta dos valores. Os sensores foram conectados à placa Arduino, e esta, por sua vez, foi conectada a um computador. Nesse experimento, os gráficos foram implementados com a linguagem Processing ${ }^{5}$, escolhida por permitir uma fácil interação com o Arduino, por ser de fácil aprendizagem e também indicada para criar imagens, animações, interações e outras manipulações gráficas.

\section{IV.1 Desenvolvendo a atividade utilizando termômetros convencionais}

A atividade experimental apresenta em ambos os arranjos dois objetivos: o primeiro é analisar por meio de um gráfico a transição do fluxo transiente para o fluxo estacionário de calor; o segundo é comparar o fluxo de calor entre materiais com diferente condutividade térmica, evidenciando qual deles é melhor condutor de calor. Para tanto, foram presos, com a ajuda de prendedores de roupa, três termômetros em cada barra, totalizando seis termômetros. A distância de cada termômetro em relação à lata, para a barra de cobre e para a barra de alumínio, é, respectivamente de $10 \mathrm{~cm}, 20 \mathrm{~cm}$ e $30 \mathrm{~cm}$. A Fig. 5 ilustra o arranjo utilizado para essa experiência.

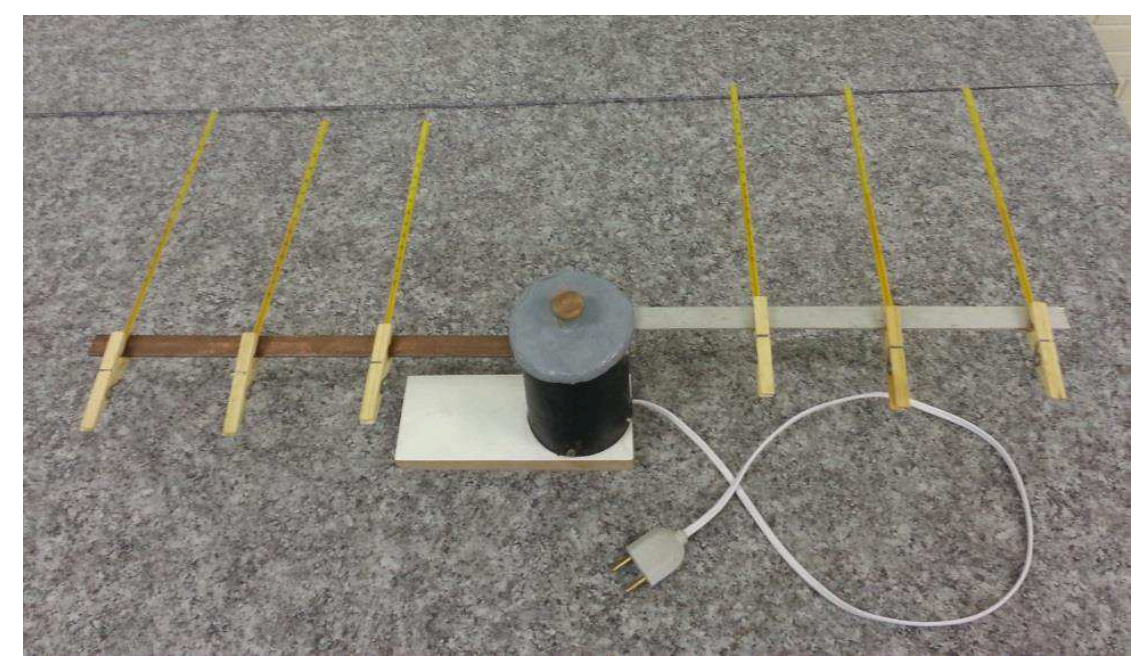

Fig. 5-Montagem da experiência com os termômetros.

\footnotetext{
$5<$ http://www.processing.org/>.
} 
Para a elaboração do gráfico, coletaram-se valores de temperatura em cada termômetro a cada 2 minutos, transcorridos num intervalo de 24 minutos. Os valores obtidos com a realização da experiência estão dispostos na tabela a seguir:

Tabela 1 - Temperatura em função do tempo para a barra de cobre e de alumínio.

\begin{tabular}{|c|c|c|c|c|c|c|c|c|c|c|c|c|c|c|c|}
\hline $\begin{array}{c}\text { Tempo } \\
(\mathrm{min})\end{array}$ & & & 0 & 2 & 4 & 6 & 8 & 10 & 12 & 14 & 16 & 18 & 20 & 22 & 24 \\
\hline \multirow{6}{*}{$\begin{array}{l}\text { Temp. } \\
\left(C^{\circ}\right)\end{array}$} & \multirow{3}{*}{$\mathrm{Cu}$} & T 1 & 16,0 & 18,0 & 27,0 & 35,5 & 43,0 & 47,0 & 51,5 & 54,0 & 56,0 & 58,5 & 59,0 & 60,5 & 61,0 \\
\hline & & Т 2 & 16,0 & 17,0 & 21,5 & 25,0 & 31,5 & 35,5 & 38,0 & 41,0 & 43,5 & 45,0 & 45,5 & 47,0 & 48,0 \\
\hline & & Т 3 & 16,0 & 16,0 & 18,5 & 21,0 & 25,0 & 29,0 & 32,5 & 35,0 & 37,5 & 39,0 & 40,0 & 40,5 & 41,0 \\
\hline & \multirow{3}{*}{$\mathrm{Al}$} & Т 1 & 16,0 & 18,0 & 25,5 & 34,0 & 40,0 & 45,5 & 47,0 & 50,0 & 52,5 & 53,0 & 54,0 & 54,0 & 54,5 \\
\hline & & Т 2 & 16,0 & 16,0 & 19,5 & 24,0 & 29,5 & 33,0 & 35,5 & 37,0 & 39,5 & 40,0 & 41,0 & 41,0 & 41,5 \\
\hline & & Т 3 & 16,0 & 16,0 & 17,0 & 20,0 & 23,0 & 27,0 & 29,5 & 31,0 & 32,5 & 33,0 & 34,0 & 34,5 & 35,0 \\
\hline
\end{tabular}

Dados: Pesquisa, 2014.

Utilizando-se a planilha de cálculo (Excel®, da Microsoft@), esses valores foram plotados no gráfico da Fig. 7.

Analisando o gráfico, assim como os dados dispostos na Tabela 1, é possível fazer algumas considerações. Percebe-se que existe uma variação de temperatura que inicialmente é bastante significativa e com o passar do tempo tende a se manter constante para cada termômetro. Podemos considerar que, no intervalo de tempo em que a temperatura é variável, o fluxo é transiente. No fluxo transiente, a quantidade de calor que entra em uma seção da barra não é a mesma que sai, ou seja, nesse caso, a quantidade que entra é maior do que a que sai. Porém, a partir de um determinado intervalo de tempo, a variação de temperatura é praticamente nula (em uma situação ideal, a temperatura não iria variar nada) e se estabelece o chamado "fluxo estacionário".

No fluxo estacionário, a temperatura em cada ponto da barra é constante e, consequentemente, a quantidade de calor que entra em uma seção da barra é a mesma que sai. No experimento, a temperatura não chegou a ser totalmente constante em cada ponto, o que pode ter ocorrido por diversos fatores, dentre os quais podem ser destacados: perda variável de calor para o meio, devido a possíveis correntes de ar no local onde foi realizada a experiência; limitações no método de se coletar os dados; precisão insuficiente nos instrumentos de medida.

Contata-se, por meio de uma análise da curva disposta no gráfico, que nos termômetros situados na barra de cobre houve uma variação maior de temperatura do que naqueles situados à mesma distância da fonte de calor na barra de alumínio. Tal fenômeno pode ser explicado pelo fato de aquele ter uma maior condutividade do que este. Sendo assim, o fluxo de calor no cobre se torna maior do que no alumínio, acarretando uma variação de temperatura mais significativa. É possível fazer algumas considerações no que diz respeito à transição do fluxo 
de calor em regime transiente para o estacionário por meio dos dados dispostos na tabela e pelo comportamento da curva no gráfico: primeiramente, percebe-se que no início do experimento a temperatura varia com uma determinada rapidez, que vai diminuindo no decorrer do tempo, até o momento em que praticamente não varia mais. Chama-se de "fluxo em regime transiente" aquele que ocorre no intervalo de tempo em que a temperatura é variável. Sendo a temperatura variável, pode-se dizer que o fluxo também é variável em cada ponto da barra. A partir do momento em que a temperatura para de variar (no nosso experimento, ela não para totalmente, mas sim tende a parar), se estabelece o chamado "fluxo em regime permanente ou estacionário", e a temperatura se mantém constante em cada ponto da barra, assim como o fluxo de energia térmica.

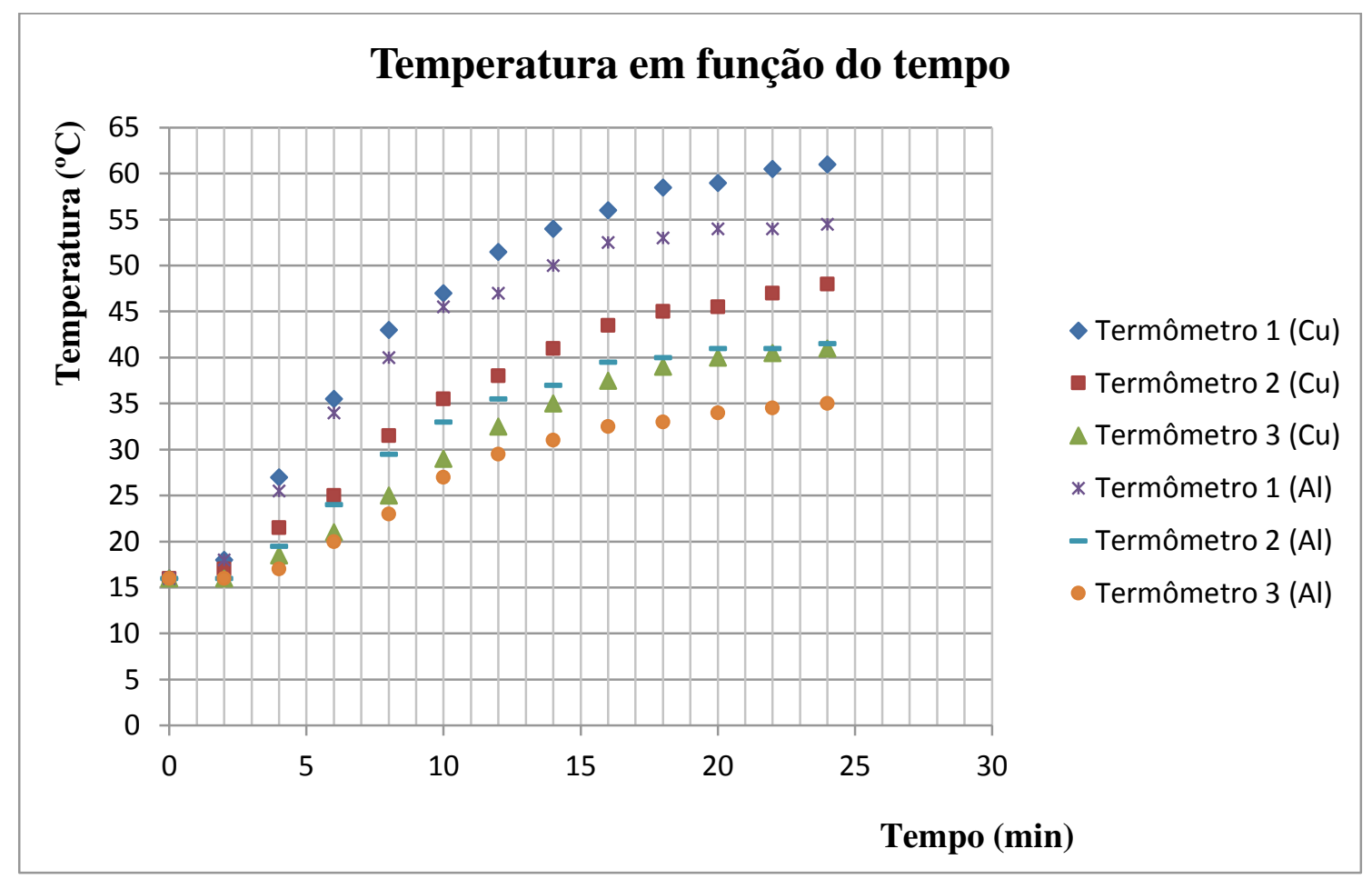

Fig. 7 - Gráfico da temperatura em função do tempo para os seis termômetros. Fonte: dados da pesquisa, 2014.

Teoricamente, para o cobre, o fluxo em regime estacionário deveria se estabelecer antes do que para o alumínio. Espera-se isso pelo fato de aquele possuir uma condutividade maior do que este. Porém, na nossa experiência, não foi possível observar essa diferença, o que pode ser explicado por diversos fatores, dentre os quais: a diferença no valor da condutividade do cobre para o alumínio é muito pequena e, consequentemente, a diferença de tempo para se estabelecer o fluxo em regime estacionário é de uma ordem muito difícil de se medir; ou ainda, explica-se o ocorrido em termos da existência de perdas variáveis de calor para o meio devido a fatores de superfície. No entanto, há de se considerar que tais fatores e limitações podem se 
mostrar, não como uma deficiência na atividade experimental, mas como elemento norteador para fomentar discussões em sala de aula, por exemplo, acerca da importância da compreensão dos fenômenos em si, uma vez que os cálculos teóricos só consideram um pequeno número de variáveis, mesmo nas simulações computacionais mais complexas.

Outro aspecto que pode ser explorado didaticamente diz respeito ao fato do tempo necessário para se estabelcer o regime estacionário. A tabela 1 ilustra que o tempo de aquecimento das barras foi 24 minutos, no entanto, esse tempo não foi suficiente para atingir o regime estacionário. Disso posto, sugere-se propor aos alunos que investiguem qual seria o tempo necessário para que essas barras atingissem o regime mencionado.

Após a realização do experimento utilizando os termômetros convencionais, foi desenvolvida a mesma atividade com auxílio de sensores de temperatura e da placa Arduino. A inserção dessas tecnologias pode se mostrar como alternativa para o professor de Física, tanto na educação básica como no ensino superior.

\section{IV.2 Inserção dos sensores de temperatura e o hardware Arduino}

Para a realização da atividade experimental nessa nova versão, recorreu-se ao mesmo equipamento didático, substituindo os termômetros por sensores de temperatura do tipo LM35. Os sensores foram conectados à placa Arduino, e esta, por sua vez, a um computador. O esquema da montagem desses elementos é mostrado na Fig. 8, complementada pela que ilustra o arranjo experimental.

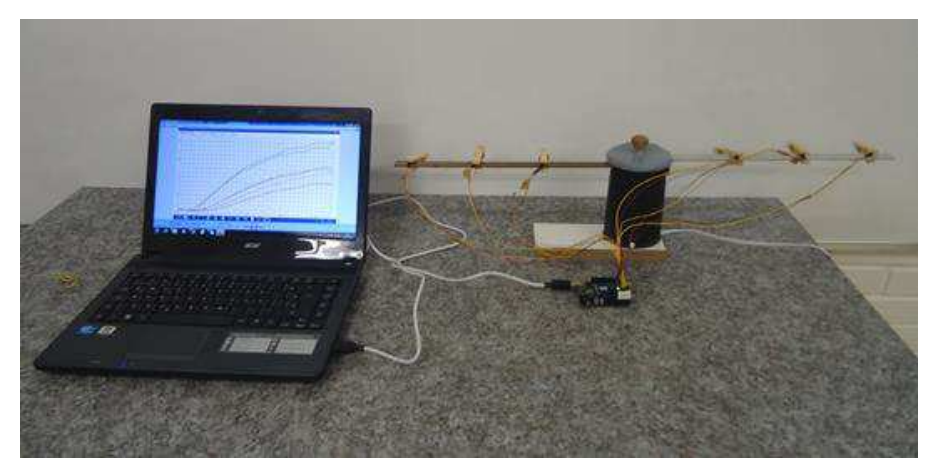

Fig. 8 - Arranjo experimental com sensores ligados à placa Arduino e está ao computador.

O sensor de temperatura LM35 possui três pinos, conforme evidenciado na Fig. 9. O pino 1 é o da alimentação (5 v), o pino 2 é o da saída analógica (valor analógico a ser interpretado pelo Arduino para obter a temperatura) e o pino 3 é o do Terra (0 v). Já na Fig. 10, podese visualizar o esquema de ligação ao Arduino dos seis sensores utilizados (três sensores em cada uma das barras metálicas). Conforme a Fig. 10, todos os pinos de alimentação (pino 1) são ligados ao pino de $5 \mathrm{v}$ de alimentação do Arduino, e todos os seis pinos do Terra (pino 3) são ligados ao Terra (GND) do Arduino. Porém, cada um dos pinos de saída analógica do LM35 é 
conectado a diferentes pinos analógicos de entrada do Arduino, a fim de se obter as distintas temperaturas de cada um dos seis sensores.

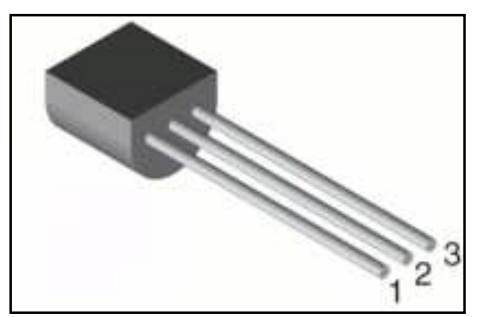

Fig. 9 - Sensor de temperatura LM35. LM35.

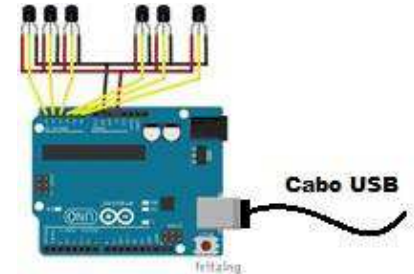

Fig. 10 - esquema de ligação dos sensores

Com o arranjo ilustrado na Fig. 8, é possível fazer seis medições de temperatura por segundo, sendo traçada a curva no gráfico, periodicamente, a cada 15 segundos. Para a montagem dos gráficos, foi desenvolvido um aplicativo em linguagem Processing cujo software encontra-se disponível em: <http://robo4edu.blogspot.com.br/2015/11/medindo-temperaturacom-lm35-e.html>. As curvas respectivas aos sensores para o cobre e o alumínio se encontram no gráfico da Fig. 11.

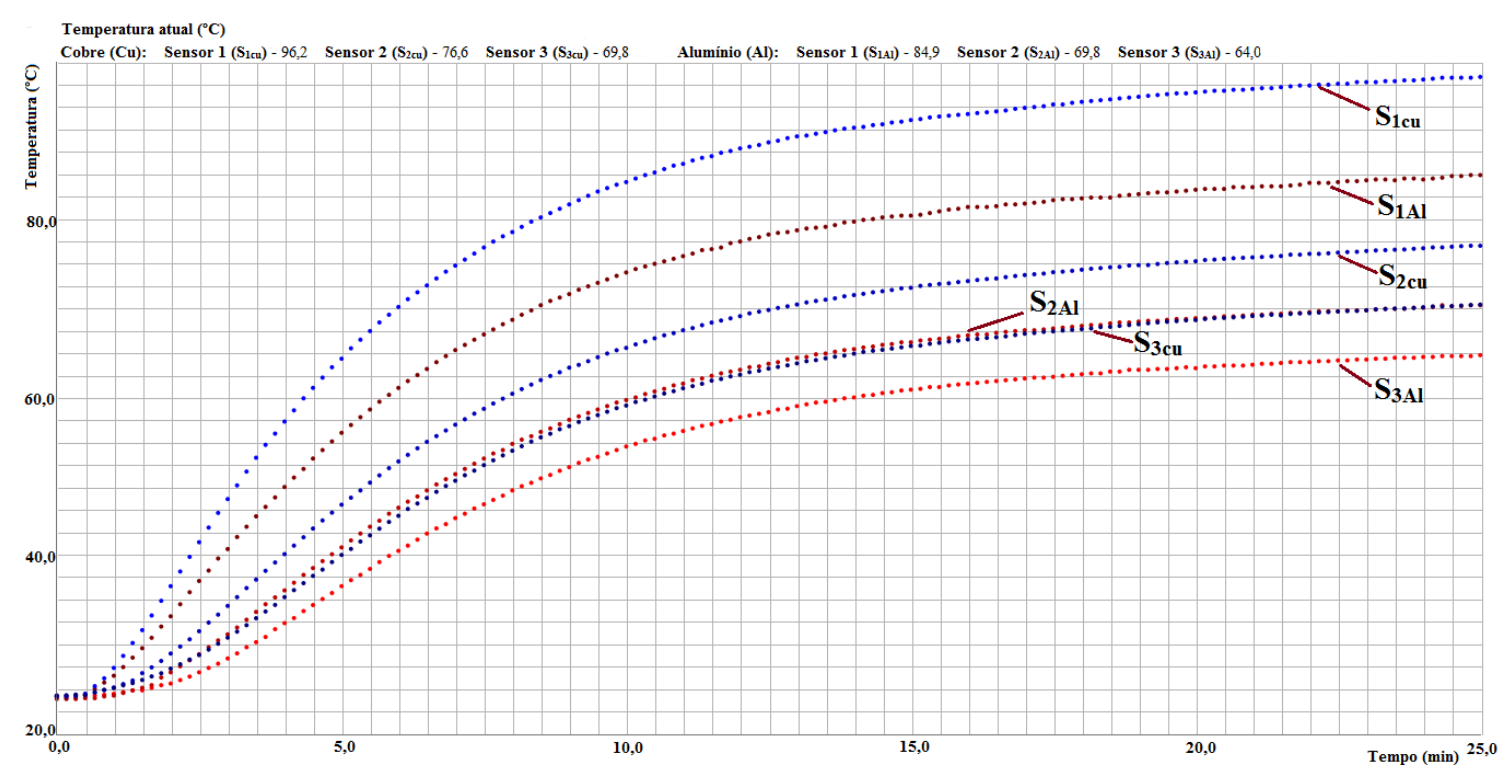

Fig. 11 - Gráfico traçado com auxílio dos sensores de temperatura.

Percebe-se que o comportamento das curvas no gráfico é bastante similar ao do experimento realizado com os termômetros. Um fator que precisa ser levado em consideração é que a curva traçada no gráfico anterior, onde se utilizou a planilha eletrônica de cálculo (Excel®, da Microsoft $\left.{ }^{\circledR}\right)$, trata-se de uma linha de tendência entre os pontos obtidos a partir dos dados 
coletados. Já o aplicativo empregado para traçar o gráfico baseado nos valores coletados pelos sensores de temperatura apenas une os pontos, e estes, por sua vez, são plotados oito vezes por segundo.

Mesmo diante de tais limitações, a atividade se mostra significativa em termos de importância para a discussão dos conceitos envolvidos no estudo, especialmente os relacionados ao regime transiente, em que se pode observar o gráfico sendo plotado em tempo real e acompanhar a evolução em direção ao regime permanente ou estacionário. Como ganho extra da atividade computacional, pode-se, por exemplo, alterar a troca de calor através de um ventilador colocado próximo ao experimento e observar o gráfico alterar-se dinamicamente.

Em termos pedagógicos, destaca-se que a realização desse experimento na versão com sensores pode ser apenas demonstrativa, assim como na versão dos termômetros permite ser realizada em pequenos grupos de trabalho. Em termos da validade de atividades demonstrativas, cujas críticas se fazem presentes na literatura, ressalta-se o mencionado por Gaspar e Monteiro (2005), no sentido de que esse tipo de atividade tem a potencialidade de despertar o interesse pela Física e de funcionar como um elemento desencadeador de interações sociais que podem servir como âncora para a construção do conhecimento por parte dos estudantes. Nessa perspectiva, considerando a possível complexidade de um arranjo envolvendo sensores, especialmente em turmas maiores, infere-se a possibilidade de que ela seja realizada de forma demonstrativa. Ainda, a oportunidade de reunir estudantes de áreas distintas como a Computação e a Física beneficia a ambos, uma vez que a troca de informações possibilita ampliar os horizontes de cada grupo sobre a aplicação de sua formação em outros campos.

\section{Considerações finais}

Como o experimento foi realizado de duas formas distintas, torna-se necessário fazer algumas considerações sobre ambas as abordagens. A primeira, realizada com os termômetros para a obtenção dos valores de temperatura, mostra-se eficaz no sentido da importância de que o estudante colete dados, monte tabelas de valores, plote gráficos e saiba analisá-los. Todo o processo pode se mostrar muito eficaz na construção do conhecimento no que diz respeito ao conteúdo específico envolvido no estudo, assim como para o desenvolvimento da capacidade do aluno de análise e crítica dos resultados, especialmente os experimentais. Porém, essa atividade leva bastante tempo para ser desenvolvida, o que, muitas vezes, dificulta sua inserção em sala de aula, principalmente na educação básica.

Em contrapartida, a inserção dos sensores e da placa Arduino assistida pelo PC pode se mostrar como um atrativo para a realização da atividade, assim como desenvolver a curiosidade dos estudantes no que diz respeito ao funcionamento dessas tecnologias. Em termos da proposta de que o experimento seja desenvolvido de maneira demonstrativa, observa-se que ele pode atuar como um instigador da curiosidade dos alunos e servir como fomento à busca por pesquisar e discutir ciência. Além disso, o uso de tecnologias, ainda que de forma demonstrativa, remete o aluno a uma aproximação da escola com as situações vivenciais e cotidianas. 
Ainda em relação à comparação entre as duas possibilidades apresentadas no estudo, destaca-se que os custos para ambos se equivalem, pois a aquisição de seis termômetros apresenta um investimento que é aproximadamente o mesmo quando se trata de adquirir os seis sensores e o Arduino, para cada exemplar. Nesse sentido, a opção por uma ou por outra possibilidade se situa mais na questão pedagógica e na identificação do professor. A esse respeito é preciso mencionar que o professor muitas vezes não tem uma identificação ou não se sente preparado para utilizar equipamentos com sensores e Arduino.

Percebe-se que, para fins pedagógicos, existe um significativo ganho cognitivo ao se realizar o experimento assistido pelo PC. No que diz respeito ao ponto de vista físico, todo o procedimento ainda precisa ser aprimorado, porém, um aspecto favorável que merece ser explorado é a precisão e a sensibilidade dos sensores. Como exemplo, menciona-se que, durante a realização do experimento, caso alguém se mova dentro da sala de aula, nas proximidades do arranjo experimental, ou abra uma porta ou janela, será possível observar uma variação de temperatura. Essa sensibilidade na realização da medida pode ser utilizada para o aprimoramento da experiência e das suas discussões, mostrando-se, além disso, uma alternativa interessante para a realização de outros experimentos relacionados com medidas de temperatura.

Como continuidade dos estudos, a investigação referente aos processos de transmissão de calor se ocupará de discutir o processo de condução térmica considerando os efeitos radiativos. Ou seja, a proposta em estudo levará em consideração a diferença na emissividade entre o cobre e o alumínio, fato não considerado nesse estudo.

\section{Referências bibliográficas}

BARREIRO, A. C. M.; BAGNATO, V. Aulas demonstrativas nos cursos básicos de Física. Caderno Catarinense de Ensino de Física, Florianópolis, v. 9, n. 3, p. 238-244, 1992.

BRASIL. Ministério da Educação. Secretária de Educação Básica. PCN+ Ensino Médio: orientações educacionais complementares aos Parâmetros Curriculares Nacionais: ciências da natureza, matemática e suas tecnologias. Brasília: Ministério da Educação, Secretária de Educação Básica, 2002.

CAVAlCANTE, M. A.; TAVOlARO, C. R. C.; MOLISANI, E. Física com Arduino para iniciantes. Revista Brasileira de Ensino de Física, v. 33, n. 4, 2011.

GASPAR, A.; MONTEIRO, I. C. C. Atividades experimentais de demonstrações em sala de aula: uma análise segundo o referencial da teoria de Vygotsky. Investigações em Ensino de Ciências, v. 10, n. 2, p. 227-254, 2005.

HEWITT, P. G. Física Conceitual. Tradução: Trieste Freire Ricci e Maria Helena Gravina. 9. ed. Porto Alegre: Bookman, 2002. 
ROSA, C. W. et al. Atividade experimental para demonstração dos fenômenos de reflexão, refração e reflexão total. REnCiMa, v. 4, n. 1, p. 75-85, 2013.

YOUNG, H. D. et al. Física. 12. ed. São Paulo: Pearson Addison Wesley, 2008-2009. 